\title{
Prediction of critical liquid loading time for water-producing gas wells: Effect of liquid drop rotation
}

\author{
Xiao Chongyang ${ }^{1,2,3} \cdot$ Fu Heng $^{1,2} \cdot$ Cheng Leli $^{4} \cdot$ Pei Wenyu ${ }^{5}$
}

Received: 31 August 2021 / Accepted: 3 December 2021 / Published online: 13 December 2021

(c) The Author(s) 2021

\begin{abstract}
After more than 20 years of continuous development, part of the wells in the Moxilei-1 gas reservoir located at the Sichuan Basin have entered the middle-later production stage. With the continuous decline in formation pressure and production rates, some of the gas wells have entered the potential period of liquid loading, while some have already suffered water plugging. Currently, the field engineers usually carry out some corresponding drainage measures after the occurrence of liquid loading in the gas well, which will first affect the production progress of the gas field, then increase the difficulty in drainage and reduce the drainage effect afterward. On the basis of Pan's model for evaluating critical liquid-carrying flow rate, the influence of liquid drop rotation was considered in the new model. Further, combined with the Arps production decline equation, a prediction model of liquid loading timing was deduced. Taking a typical well in the Moxilei-1 gas reservoir as an example, based on the early-stage production data of the gas well, the model was used to predict the liquid loading timing accurately. The model can predict the possibility and timing of liquid loading in gas wells at different production stages. It can check the gas wells with potential liquid loading, so as to reduce the workload for field workers. Furthermore, it can predict the potential liquid accumulation and its timing in advance, so as to guide the field workers to prepare for drainage in advance.
\end{abstract}

Keywords Critical liquid-carrying flow model $\cdot$ Liquid drop rotation · Production decline equation · Liquid loading timing · Water-producing well

\section{Introduction}

The Moxilei-1 gas reservoir is characterized by low permeability, edge water and sulfur content. In the early stage of development, vertical wells are mainly used. In the middle and late stage of production, it is difficult to bring out the water in the wellbore smoothly due to the rapid decline in production rate. Therefore, it is very easy to accumulate

Fu Heng

doublesun_show@163.com

1 College of Energy, Chengdu University of Technology, Chengdu 610059, China

2 State Key Laboratory of Oil and Gas Reservoir Geology and Exploration, Chengdu 610059, Sichuan, China

3 Northwest Oilfield Branch Company, SINOPEC, Urumqi 830011, China

4 Institute of Logging Technology and Engineering, Yangtze University, Jingzhou 434023, Hubei, China

5 PIPECHINA Oil and Gas Control Center, 5 Dongtucheng Road, Chaoyang District, Beijing, China fluid at the well bottom, increase the back-pressure of the production layer, further reduce the production efficiency of the gas well, then block the wellbore by direct water flooding and damage the formation near the bottom of the well. At present, the corresponding water plugging, water control and drainage measures will be implemented only when the production gas well has effusion symptoms or is completely blocked. On the one hand, the passive implementation of drainage measures will affect the production progress of gas field. On the other hand, it will increase the difficulty in drainage and reduce the drainage effect; in addition, it will increase the workload of field staff and the production cost of single well (Beibei et al. 2013). Therefore, it is very important to accurately predict the liquid loading timing of wellbore for the development and production of oil and gas fields.

At present, direct and indirect methods are mainly used to identify whether the gas well is liquid accumulating or not. The direct methods include visual judgment method, measured pressure gradient curve method, etc. And the indirect methods include critical liquid-carrying model method, condensate 
water calculation method, well test curve analysis method, etc. (Haitao 2017, 2019; Sun et al. 2019a). The critical liquidcarrying model method has a wide range of applications and good application effect (Rui et al. 2019). The critical liquidcarrying model method includes (Rui et al. 2019; Turner et al. 1969; Li et al. 2010, 2001; Jie et al. 2018; Coleman et al. 1991; Min et al. 2001; Chaoyang 2010; Desheng, et al. 2014; Zhibin and Yingchuan 2012; Gang 2014; Sun et al. 2020): (1) the spheroidal droplet model, in which the Turner model is the most classic, but in the actual situation, the circular droplet will be affected by the upper and lower pressure difference in the process of rising in the wellbore, and the droplet will turn to ellipsoidal, so the prediction result of this kind of model is often too large compared with the realistic case ( $\mathrm{Li}$ et al. 2010; Jie et al. 2018; Coleman et al. 1991), and (2) the ellipsoidal droplet model, in which the Limin model is the most classic (Li et al. 2001; Min et al. 2001), can predict accurately. It is widely used to measure the critical liquid-carrying capacity of gas well, but it ignores the energy loss caused by the tumble of droplets during the rising process ( $\mathrm{Li}$ et al. 2010). Generally speaking, the critical liquid-carrying model only gives the critical production when the gas well accumulates fluid, and does not propose a targeted prediction method combined with the gas well's own energy. This kind of method cannot predict the specific liquid loading time of gas well in advance and effectively, and its prediction effect is poor for the gas wells with irregular production data and that with violent fluctuation (Sun et al. 2021; Sheikholeslami and Jafaryar 2020; Sheikholeslami and Farshad 2021; Said et al. 2021).

On the basis of Pan's critical liquid-carrying capacity model, the influence of droplet rolling is considered (Li et al. 2010; Jie et al. 2018), and then, combined with Arps production decline equation (Wang et al. 2017, 2020), the prediction model of effusion time in water-producing gas wells is derived. Taking a typical well in Moxilei-1 gas reservoir as an example, based on the production data of the gas well at the early stage, the model is used to predict the time of liquid accumulation and plugging in the gas well accurately. The model can predict the possibility of liquid accumulation in gas wells at different production stages and can reduce the workload of field staff by targeted investigation of gas wells with possible liquid accumulation. In addition, it can predict the gas wells with possible liquid accumulation and the time of liquid accumulation in advance, so as to guide the field staff to prepare for liquid drainage and implement corresponding measures in advance.

\section{Prediction model of liquid loading time in water-producing gas well}

Awolusi (2006) and Wei (Na 2007) obtained the following understanding through relevant wellbore fluid-carrying experiments:
1. During the rising process, the droplet will exist as an ellipsoid due to the influence of the pressure difference between the upper and lower parts;

2. During the rising process of ellipsoidal droplets in the wellbore, the pressure difference between the two ends of the droplets is unbalanced, which causes the droplets to roll up and down disorderly, and consumes the gascarrying energy, which reduces the gas-carrying efficiency.

Therefore, the droplets carried by gas flow in the gas wellbore are ellipsoidal, and the energy loss caused by droplet rolling cannot be ignored.

\section{Ellipsoidal droplet model considering rolling}

\section{(1) Advantages and disadvantages of traditional ellipsoidal} droplet models

The ellipsoidal droplet model is based on the Turner model, which is the most studied and classic critical liquid-carrying flow model (Rui et al. 2019). Statistics of some spheroid models and ellipsoid models are summarized in Table 1. It can be found that although the ellipsoid model considers many factors, it does not consider the influence of rolling in the process of droplet rising.

Li et al. (2010) and others consider that the gas-carrying flow rate after considering droplet rolling is between the calculation results of Li's ellipsoid model and Coleman's spheroid model, and the energy loss caused by droplet rolling is characterized by adding a correction factor, as follows:

$v_{\mathrm{H}}=v_{\mathrm{L}}+s\left(v_{\mathrm{T}}-v_{\mathrm{L}}\right)$

In the above formula, $V_{H}, V_{L}$ and $V_{T}$ are the critical liquid loading velocity in He's model, Li's model and Turner model, respectively, fall into the range from $0 \sim 1$. And $s$ is the correction factor in He's model. The larger the correction factor is, the smaller the energy loss caused by rolling is. According to a large number of field production examples, Li et al. (2010) obtained that the empirical correction factor was equal to 0.83 . He's model is based on Li's model and Turner model. These two basic models ignore the influence of droplet deformation, temperature, pressure and other factors and limit the prediction results between the two models. Moreover, He's model contains empirical parameters. Generally speaking, the application scope of the model has great limitations.

\section{(2) An ellipsoidal droplet model considering rolling}

According to the research of Jie et al. (2018), the calculation formula of the maximum windward surface diameter after considering the droplet deformation is as follows: 
Table 1 Part of classical spheroid model and ellipsoid model

\begin{tabular}{|c|c|c|}
\hline Time & Model & Model features \\
\hline 1969 & Turner model (Turner et al. 1969) & $\begin{array}{l}\text { The droplet is a round sphere, which is the most classic, but the prediction result is too large. It } \\
\text { is suitable for wells with high gas-liquid ratio and foggy flow }\end{array}$ \\
\hline 1991 & Coleman model (Coleman et al. 1991) & $\begin{array}{l}\text { According to Turner model, the droplet is a sphere, which is suitable for wellhead pressure } \\
\text { less than } 3.25 \mathrm{mpa}\end{array}$ \\
\hline 2001 & Li model (Li et al. 2001; Min et al. 2001) & According to Turner model, the droplet is ellipsoid \\
\hline 2010 & Chaoyang model (Chaoyang 2010) & According to Turner model, the droplet is an ellipsoid with aspect ratio of 0.9 \\
\hline 2010 & Desheng model (Desheng et al. 2014) & According to Turner model, small droplets aggregate into large droplets \\
\hline 2012 & $\begin{array}{l}\text { Zhibin and Yingchuan model (Zhibin } \\
\text { and Yingchuan 2012) }\end{array}$ & $\begin{array}{l}\text { The droplet is an ellipsoid, and the deformation and the maximum size difference of the drop- } \\
\text { let are considered }\end{array}$ \\
\hline 2014 & Gang model (Gang 2014) & $\begin{array}{l}\text { The droplet is an ellipsoid, and the influence of temperature and pressure on the interfacial } \\
\text { tension is considered }\end{array}$ \\
\hline 2018 & Jie model (Jie et al. 2018) & $\begin{array}{l}\text { The droplet is an ellipsoid. The deformation of the droplet and its effect on the surface free } \\
\text { energy of the droplet are considered }\end{array}$ \\
\hline
\end{tabular}

$d=\frac{4\left(2 K^{3}+4\right) \sigma v_{\mathrm{sl}}}{3 f_{\mathrm{sg}} \rho_{\mathrm{g}} \nu_{\mathrm{sg}}^{3} K}$

In the above formula, $K$ is the droplet deformation parameter, with the calculation formula $\left(K=d_{E} / d_{B}\right)$, is the windward surface diameter of ellipsoidal droplet, $d_{B}$ is the diameter of spherical droplet, $\mathrm{m}$, and $d$ is the windward surface diameter of droplet, $\mathrm{m}$. When $\mathrm{K}=1, d$ is the diameter of spherical droplet; when $\mathrm{K} \neq 1, d$ is the windward surface diameter of ellipsoidal droplet. $\nu_{\mathrm{sl}}$ and $v_{\mathrm{sg}}$, respectively, show the apparent velocity of liquid phase and gas phase, $\mathrm{m} / \mathrm{s}$. $\sigma$ represents the surface tension coefficient of gas-liquid interface, $\mathrm{N} / \mathrm{m} . f_{\text {sg }}$ represents the surface tension coefficient of gas-liquid interface, $N / \mathrm{m} . \rho_{\mathrm{g}}$ denotes the density of the gas, $\mathrm{kg} / \mathrm{m}^{3}$.

Assuming that the horizontal section of the ellipsoid droplet is circular, the vertical section is elliptical, and the ellipsoid surface is smooth, as depicted in Fig. 1. Then, in the vertical wellbore, the ellipsoid droplet will be affected by buoyancy, drag and gravity simultaneously.

$F_{\mathrm{D}}+F_{\mathrm{g}}-G=0$

In the above formula, $F_{D}$ denotes drag force, $F_{g}$ denotes buoyancy, and $G$ denotes gravity, N.

The drag force calculation formula is as follows:

$F_{\mathrm{D}}=\frac{1}{2} C_{\mathrm{D}} S_{\mathrm{E}} \rho_{\mathrm{g}} v_{\mathrm{c}}^{2}$

In the above formula, $V c$ is the critical liquid-carrying velocity, $\mathrm{m} / \mathrm{s}$. $C_{D}$ is the drag coefficient. $S_{E}$ is the windward surface area of the droplet, $\mathrm{m}^{2}$, which can be expressed by the following formula (Jie et al. 2018):

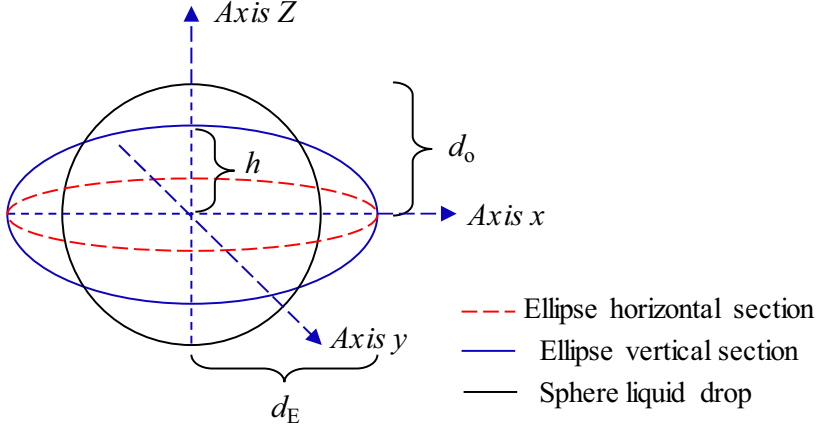

Fig. 1 Schematic diagram of the model of spherical droplet changing into ellipsoidal droplet

$S_{\mathrm{E}}=\frac{4}{9} \pi\left[\frac{\left(2 K^{3}+4\right) \sigma v_{\mathrm{sl}}}{f_{\mathrm{sg}} \rho_{\mathrm{g}} \nu_{\mathrm{sg}}^{3} K}\right]^{2}$

However, under the combined action of various forces in the wellbore, the droplets not only move along the wellbore axis but also rotate. That is to say, the carrying effect of various forces on the droplets is not only transformed into the translational kinetic energy of the droplets, but also into the rotational kinetic energy of the droplets $(\mathrm{Li}$ et al. 2010; Awolusi , 2006; Na 2007; Sun et al. 2019b; Xiangguo et al. 2021). Assuming the droplet rotates uniformly along the $\mathrm{Y}$-axis and the rotational angular velocity is $w \mathrm{rad} / \mathrm{s}$, the rotational kinetic energy is:

$E_{w}=\frac{1}{8} m d_{\mathrm{E}}^{2} w^{2}$

Assuming that the droplet rises at a constant speed and the velocity is $V_{C D} \mathrm{~m} / \mathrm{s}$, the translational kinetic energy of the droplet is: 
$E_{\mathrm{D}}=\frac{1}{2} m v_{\mathrm{cD}}^{2}$

The predecessors neglected part of the energy consumed by the droplet in rotation. That is to say, all the energy generated by the combined action of various forces on the droplet is converted into the translational kinetic energy of the droplet, which can be expressed by the following formula:

$\frac{1}{2} m v_{\mathrm{c}}^{2}=\frac{1}{2} m v_{\mathrm{cD}}^{2}+\frac{1}{8} m d_{\mathrm{E}}^{2} w^{2}$

In other words, the critical carrying velocity $V_{C}$ should be greater than the rising velocity $V_{C D}$ of the droplet and can offset the energy consumed by the rotation of the droplet (Sun et al. 2018, 2017), so as to successfully carry the droplet out of the wellhead. Suppose that $\eta$ is the liquidcarrying efficiency of the gas, then there exists the following equation:

$\eta=\frac{v_{\mathrm{cD}}^{2}}{v_{\mathrm{c}}^{2}}=\frac{4 v_{\mathrm{cD}}^{2}}{4 v_{\mathrm{cD}}^{2}+d_{\mathrm{E}}^{2} w^{2}}$

The rolling phenomenon of droplets during the process of lifting is common, the main reason is that the rising gas is not uniform and continuous, and the droplets are not evenly distributed in the wellbore. Also, the droplets are not standard ellipsoid or spherical, so the force on the droplets is not balanced, and the droplets will collide with the wellbore wall in the process of lifting, so the droplets will roll in the process of lifting. There are many influencing factors of droplet rolling, and the current research results can only qualitatively describe the phenomenon, but it is difficult to measure and quantify, so it can only be determined based on field experience. According to the related research of $\mathrm{Li}$ et al. (2010), the critical carrying velocity of droplet rolling is 1.996 times that of Li's model. Because Li's model does not consider the energy loss caused by droplet rolling, that is to say, the critical liquid-carrying velocity after droplet rolling is considered to be $0.5, \eta$ is about 0.5 .

The formula of traction force after rolling is as follows:

$F_{\mathrm{D}}=\frac{1}{2} C_{\mathrm{D}} S_{\mathrm{E}} \rho_{\mathrm{g}} v_{\mathrm{cD}}^{2}=\frac{1}{2} \eta C_{\mathrm{D}} S_{\mathrm{E}} \rho_{\mathrm{g}} v_{\mathrm{c}}^{2}$

Substituting the gravity calculation formula, buoyancy calculation formula and formula (10) into formula (3) yields:

$\frac{1}{2} \eta C_{\mathrm{D}} S_{\mathrm{E}} \rho_{\mathrm{g}} \nu_{\mathrm{c}}^{2}+\frac{1}{6} \pi d_{\mathrm{B}}^{3} \rho_{\mathrm{g}} g-\frac{1}{6} \pi d_{\mathrm{B}}^{3} \rho_{l} g=0$

where $\rho_{l}$ is the density of mineralized water, $\mathrm{kg} / \mathrm{m}^{3}$. Furthermore, by substituting formula (5) into the above formula (11) and simplifying it, we can obtain the model based on Pan's critical liquid-carrying velocity and consider the critical liquid-carrying velocity of gas after droplet rolling. $v_{\mathrm{c}}=\frac{6.89 K}{\left(K^{3}+2\right) \sqrt{\eta C_{\mathrm{D}}}}\left(\frac{\sigma\left(\rho_{l}-\rho_{\mathrm{g}}\right)}{\rho_{\mathrm{g}}{ }^{2}}\right)^{0.25}$

\section{Prediction model of liquid loading time in water-producing gas well}

According to the critical liquid-carrying velocity of gas, the formula of critical liquid-carrying flux can be obtained as follows:

$q_{\mathrm{c}}=2.5 \times 10^{8} \frac{p A v_{\mathrm{c}}}{Z T}$

In the above formula, $q_{c}$ represents the critical liquid-carrying capacity of gas, $\mathrm{m}^{3} / \mathrm{D} ; A$ represents the cross-sectional area of flow channel, $\mathrm{m}^{2} ; p$ represents the wellhead pressure, $\mathrm{MPa} ; Z$ represents the compressibility of gas; and $T$ represents the thermodynamic temperature, $\mathrm{K}$.

The classical production decline model (Wang et al. 2017, 2020) of Arps is as follows:

$q=\frac{q_{\mathrm{r}}}{\left(1+b D_{\mathrm{r}} t\right)^{1 / b}}$

In the above formula, $q_{r}$ refers to the production of the gas well at the beginning of decline, $\mathrm{m}^{3} / \mathrm{D}$. $b$ denotes decline index, dimensionless. $D_{r}$ denotes the decline rate, $\mathrm{d}^{-1} . t$ denotes the decline time, D.

Assuming that production rate of a gas well decreases to a certain extent, which is just the critical liquid-carrying capacity, the time $\left(t_{c}\right)$ when the gas well decreases to the critical liquid-carrying capacity can be calculated.

$t_{\mathrm{c}}=\frac{\left(\frac{z T q_{\mathrm{r}}}{2.5 \times 10^{8} p A v_{\mathrm{c}}}\right)^{b}-1}{b D_{\mathrm{r}}}$

The model can be used to predict the possibility of fluid accumulation at different stages of gas production well.

\section{Model comparison and field application}

\section{Comparison with Pan's model}

\section{(1) Analysis of the influence of droplet rolling on the critical liquid-carrying capacity}

Table 1 shows that Pan's model is an ellipsoidal droplet model with comprehensive consideration at present. The proposed model in this paper is improved on the basis of Pan's model, so the model in this paper is compared with Pan's model. It is verified by the relevant calculation 
parameters of a vertical gas well at which has been flooded in Moxilei-1 gas reservoir; relevant physical properties are collected in Table 2. In addition, the drag coefficient, deformation parameter, critical Weber number, surface tension considering the influences of pressure and temperature, and natural gas density are calculated as follows (Jie et al. 2018; Zhibin and Yingchuan 2012):

Drag coefficient $C_{D}$ :

$C_{\mathrm{D}}=0.36[1+2.632(K-1)]$

Deformation parameters $K$ :

$\mathrm{We}_{\mathrm{c}}=\frac{16 \pi\left(\frac{2+K^{3}}{3 K}-1\right)}{7.951-\frac{2.744}{K^{2}}+\frac{0.3077}{K}-5.117 K+0.501 K^{2}}$

Weber number $\mathrm{We}_{\mathrm{C}}$ :

$\mathrm{We}_{\mathrm{c}}=\frac{5.14 \rho_{g} \nu_{\mathrm{sg}}^{2}}{\sigma} \sqrt{\frac{\sigma}{\rho_{l} g}}\left[15.4\left(\frac{\sigma}{\rho_{l} \nu_{\mathrm{sg}}^{2}} \sqrt{\frac{\rho_{l} g}{\sigma}}\right)^{0.58}+\frac{3.5 G_{\mathrm{le}}}{\rho_{l} \nu_{\mathrm{sg}}}\right]$

Surface tension $\sigma$ :

$\sigma\left(T_{\mathrm{s}}\right)=\frac{1.8\left(137.78-T_{\mathrm{s}}\right)}{206}[\sigma(23.33)-\sigma(137.78)]+\sigma(137.78)$

Natural gas density $\rho_{\mathrm{g}}$ :

$\rho_{g}=3484.4 \frac{\gamma_{\mathrm{g}} p}{Z T}$

In the above formula, $\sigma\left(\mathrm{T}_{\mathrm{S}}\right)$ is the surface tension of water at specific temperature, $\mathrm{mN} / \mathrm{m} . \gamma_{\mathrm{g}}$ is the relative density of natural gas. $v_{\mathrm{sg}}$ is the apparent velocity of gas phase, $\mathrm{m} / \mathrm{s}$. $G_{l \mathrm{e}}$ is the mass flow rate of droplet, $\mathrm{kg} /\left(\mathrm{m}^{2} \cdot \mathrm{s}\right)$.

Then, according to the relevant calculation parameters in Table 2, the Pan's model and the model in this paper, the critical liquid-carrying flow comparison curves under different deformation parameters and rolling energy consumption can be obtained, as shown in Fig. 2. It can be observed that the closer the droplet is to the sphere, the greater the critical liquid-carrying capacity, and the more obvious the energy consumption caused by the droplet rolling. In addition, the more obvious the droplet rolling is, the greater the gas flow is needed to carry the droplet out of the wellhead.
And the more obvious the ellipsoid shape of the droplet is, the smaller the critical liquid-carrying capacity is, and the smaller the possibility of liquid accumulation is.

\section{(2) Example comparison}

The accuracy of this model and Pan's model is compared by using the example data. For the convenience of calculation and simple comparison between Pan's model and this model, assuming that the deformation parameter $(K)$ is constant as 1.4 , the drag coefficient $\left(C_{D}\right)$ is 0.739 . The relevant parameters and calculation results are shown in Table 3.

\section{Case application: a case study of Moxilei-1 gas reservoir}

\section{(1) Prediction of critical liquid-carrying capacity}

To verify the rationality of the model proposed in this paper, a vertical gas well A in Moxilei-1 gas reservoir is used for verification. The wellhead temperature $T$ is $330 \mathrm{k}$, the average compressibility factor $Z$ is 1.02 , the inner diameter of tubing is $0.062 \mathrm{~m}$, the relative density of natural gas is 0.65 , and the mineralized water density is $1100 \mathrm{~kg} / \mathrm{m}^{3}$. In addition, assuming the deformation parameter is a constant as 1.8, the drag coefficient is 1.118 , and the comparison curve between the critical liquid-carrying flow rate and the actual flow rate of well A can be obtained (Fig. 3).

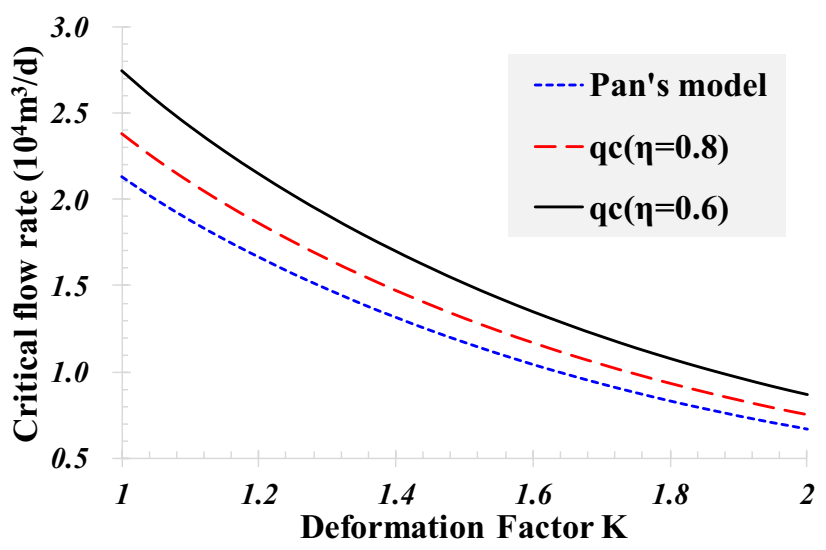

Fig. 2 Critical gas-carrying flow rate considering droplet rolling

Table 2 Relevant calculation parameters of critical liquid-carrying model

\begin{tabular}{llll}
\hline Relevant parameters in wellbore & Numerical value & Relevant parameters in wellbore & Numerical value \\
\hline Average temperature $T(k)$ & 320 & Relative density of natural gas $\gamma_{\mathrm{g}}$ & 0.65 \\
Average compression factor Z & 0.82 & Mineralized water density $\rho_{l}\left(\mathrm{~kg} / \mathrm{m}^{3}\right)$ & 1100 \\
Inner diameter of oil pipe $(\mathrm{m})$ & 0.062 & Wellhead pressure $P(\mathrm{MPa})$ & 5 \\
\hline
\end{tabular}


Table 3 Application comparison of this model and Pan's model

\begin{tabular}{lllllll}
\hline $\begin{array}{l}\text { Serial num- } \\
\text { ber }\end{array}$ & $\begin{array}{l}\text { Wellhead pressure } \\
(\mathrm{MPa})\end{array}$ & $\begin{array}{l}\text { Wellhead tempera- } \\
\text { ture }(\mathrm{K})\end{array}$ & $\begin{array}{l}\text { Gas production } \\
\left(10^{4} \mathrm{~m}^{3} / \mathrm{d}\right)\end{array}$ & Production situation & $\begin{array}{l}\text { This model } \\
\left(10^{4} \mathrm{~m}^{3} / \mathrm{d}\right)\end{array}$ & $\begin{array}{l}\text { Pan's model } \\
\left(10^{4} \mathrm{~m}^{3} / \mathrm{d}\right)\end{array}$ \\
\hline 1 & 1.88 & 292.8 & 1.88 & Close to liquid accumulation & 1.41 & 0.99 \\
2 & 2.2 & 291 & 3 & Continuous liquid-carrying & 1.52 & 3.51 \\
3 & 16.3 & 293 & 3.4 & Close to liquid accumulation & 3.51 & 3.51 \\
4 & 16.3 & 292.2 & 4.3 & Continuous liquid-carrying & 2.48 \\
5 & 1.43 & 291 & 1.16 & Liquid accumulation & 1.24 & 0.87 \\
6 & 10.5 & 292 & 2.8 & Close to liquid accumulation & 3.02 & 2.13 \\
7 & 4 & 290.8 & 2.88 & Continuous liquid-carrying & 2.01 \\
\hline
\end{tabular}

Figure 3 shows that the Pan's model predicts that the well has accumulated fluid at 2000-3000 days, but in fact, the well has not accumulated fluid in this period, and the timing for realistic fluid accumulation is about 3000 days. It is obvious that the model proposed in this paper is more reasonable than Pan's model.

\section{(2) Prediction of gas well liquid loading time}

According to this model, the critical liquid-carrying capacity of well A is calculated to be about $1.1 \times 10^{4} \mathrm{~m}^{3}$. The Arps decline equation is used to fit the historical production data over 2000 days, and the time when the gas production of the well decreases to the critical liquid-carrying capacity is predicted. Finally, it is compared with the actual gas production curve and the actual liquid accumulation time. The fitting and prediction results are shown in Fig. 4. The results are as follows: decline index $\mathrm{b}=0.9$, decline rate $D_{r}=0.065 \mathrm{D}^{-1}$. The time of gas production decreasing to $1.1 \times 10^{4} \mathrm{~m}^{3}$ is close to $2913 \mathrm{~d}$, that is, the possible start time of fluid accumulation in well
A is 2913 days, which is close to the actual time of fluid accumulation in well A of 3000 days. It indicates that this method can reasonably predict the time of fluid accumulation in gas wells in advance.

\section{Summary and conclusions}

1. During the rising process of the droplets in the wellbore of gas well, due to the unbalanced torque, the droplets keep rolling up and down, which consumes the energy of carrying liquid and reduces the efficiency of liquid loading. Considering the influence of droplet rolling, the new model is more reasonable than existed Pan's model.

2. Combined with Arps production decline equation and new critical liquid-carrying model, a prediction model of liquid loading time for water-producing gas wells is proposed. The model can accurately predict the possibility and timing of liquid accumulation at different production stages.
Fig. 3 Comparison of the prediction results of this model and Pan's model with the effusion time of well A in Moxilei-1 gas reservoir

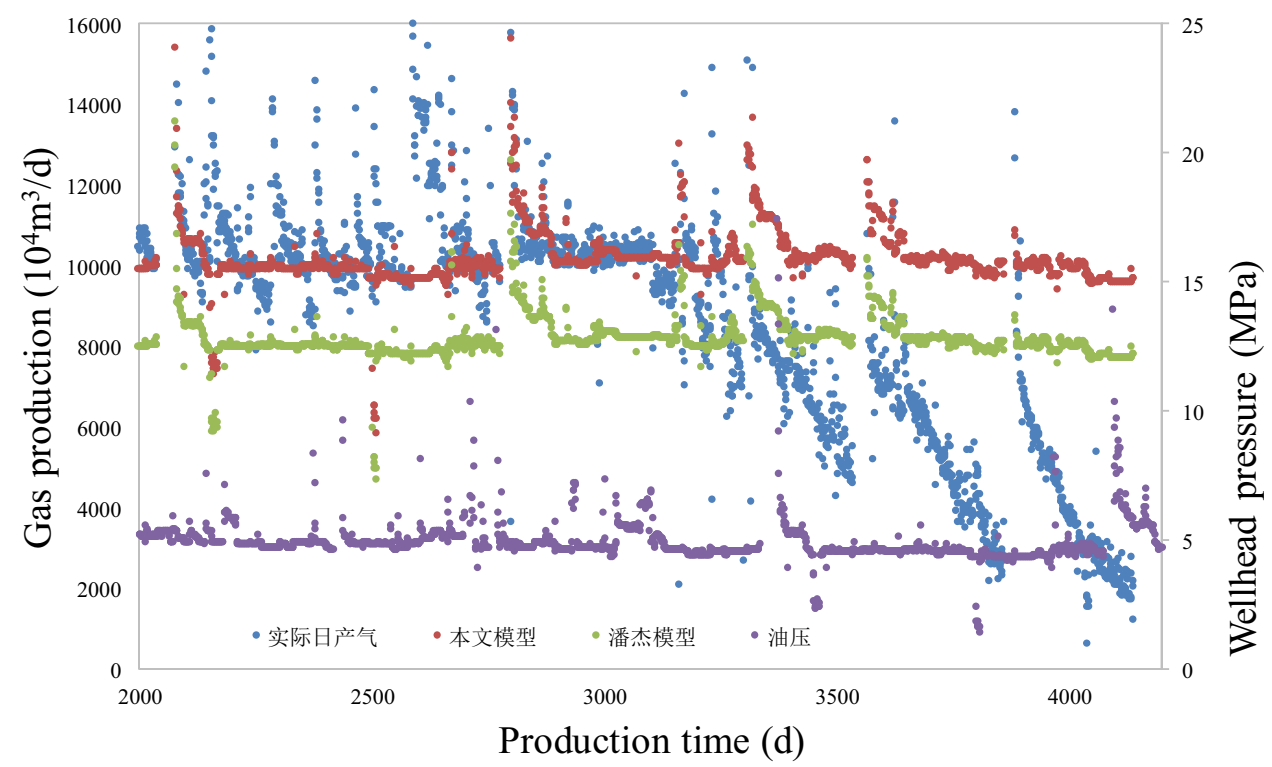


Fig. 4 Prediction of accumulation time in well A by combining ARPS production decline equation and critical liquidcarrying flow rate

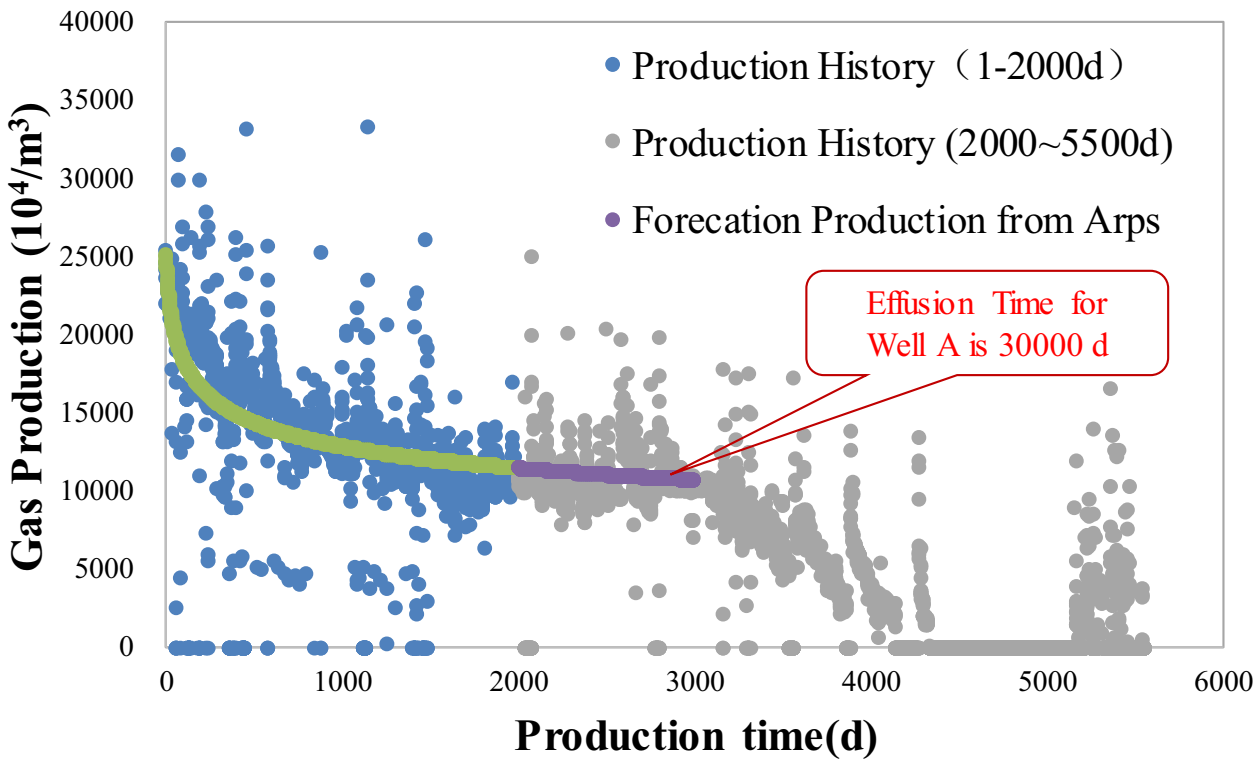

Acknowledgements The authors would like to acknowledge the financial support from State Key Laboratory of Petroleum Resources and Prospecting (No. PRP/open-2104).

Funding The funding was grant by State Key Laboratory of Petroleum Resources and Prospecting (PRP/open-2104).

Conflict of interests The author(s) declare(s) that there is no conflict of interest regarding the publication of this paper.

Ethical statement On behalf of all the co-authors, the corresponding author states that there are no ethical statements contained in the manuscripts

Open Access This article is licensed under a Creative Commons Attribution 4.0 International License, which permits use, sharing, adaptation, distribution and reproduction in any medium or format, as long as you give appropriate credit to the original author(s) and the source, provide a link to the Creative Commons licence, and indicate if changes were made. The images or other third party material in this article are included in the article's Creative Commons licence, unless indicated otherwise in a credit line to the material. If material is not included in the article's Creative Commons licence and your intended use is not permitted by statutory regulation or exceeds the permitted use, you will need to obtain permission directly from the copyright holder. To view a copy of this licence, visit http://creativecommons.org/licenses/by/4.0/.

\section{References}

Awolusi O (2006) Resolving discrepancies in predicting critical rates in low pressure stripper gas wells. Master Thesis, Texas Tech University

Beibei J, Haitao Li, Zhouzhou Y, Yusheng J, Tianqi Z (2013) A new method for optimization of drainage and production measures of water well in su59 block. Oil Drill Prod Technol 35(05):79-83
Chaoyang P (2010) Study on the critical flow rate of liquid carrying in gas wells. Xinjiang Pet Geol 31(1):72-74

Coleman SB, Clay HB, Mccurdy DG, Lii LN (1991) A New look at predicting gas-well load-up. JPT 43(3):329-333

Desheng Z, Weipeng Z, Jianxun L et al (2014) Study on multi droplet model of fluid carrying in gas wells. Hydrodyn Res Progress 29(5):572-579

Gang L (2014) A new method for calculating the critical flow rate of fluid carrying in gas wells. Fault Block Oil and Gas Fields 21(3):339-340

Haitao Li (2017) Natural gas engineering. Petroleum Industry Press, Beijing

Haitao L, Nianyin L (2019) Oil production engineering. Petroleum Industry Press, Beijing

Jie P, WuJie W, Yaoqi W, Junbin C, Liangliang W (2018) Calculation model of critical liquid carrying velocity of gas well considering the influence of droplet shape. Nat Gas Ind 38(01):67-73

Li HS, Hua LG, Zhi Y, Juan GY, Hao SY, Jing GX (2010) A new model for predicting fluid accumulation in low pressure gas wells. Oil Gas Well Test 19(05):9-13

Li M, Sun L, Li S L. New view on continuous-removal liquids from gas wells. In: SPE Permian Basin Oil and Gas Recovery Conference. Midland, Texas, USA, Society of Petroleum Engineers, 2001: 1-6

Min L, Lei S, Shilun L (2001) A new model of gas well continuous drainage. Nat Gas Ind 21(5):61-63

$\mathrm{Na} W$ (2007) Visualization experimental study of gas well effusion. Southwest Petroleum University

Rui W, Yun Ma, Liangbin D, Jiarui C, Ningsheng Z (2019) Research progress on critical fluid carrying and accumulation models of water producing gas wells. Sci Technol Eng 19(33):10-20

Said Z, Sundar LS, Tiwari AK, Ali HM, Sheikholeslami M, Bellos E, Babar H (2021) Recent advances on the fundamental physical phenomena behind stability, dynamic motion, thermophysical properties, heat transport, applications, and challenges of nanofluids. Phys Rep

Sheikholeslami M, Farshad SA (2021) Numerical simulation of effect of non-uniform solar irradiation on nanofluid turbulent flow. Int Commun Heat Mass Transf 129:105648

Sheikholeslami M, Jafaryar M (2020) Nanoparticles for improving the efficiency of heat recovery unit involving entropy generation analysis. J Taiwan Inst Chem Eng 115:96-107 
Sun Z, Li X, Shi J, Zhang T, Sun F (2017) Apparent permeability model for real gas transport through shale gas reservoirs considering water distribution characteristic. Int J Heat Mass Transf 115:1008-1019

Sun Z, Li X, Shi J, Zhang T, Feng D, Sun F, Li L (2018) A semi-analytical model for the relationship between pressure and saturation in the CBM reservoirs. J Natl Gas Sci Eng 49:365-375

Sun Z, Shi J, Wu K, Zhang T, Feng D, Li X (2019a) Effect of pressurepropagation behavior on production performance: implication for advancing low-permeability coalbed-methane recovery. SPE J 24(02):681-697

Sun Z, Wu K, Shi J, Zhang T, Feng D, Wang S, Liu W, Mao S, Li X (2019) Effect of pore geometry on nanoconfined water transport behavior. AIChE J 65(8):e16613

Sun Z, Li X, Liu W, Zhang T, He M, Nasrabadi H (2020) Molecular dynamics of methane flow behavior through realistic organic nanopores under geologic shale condition: Pore size and kerogen types. Chem Eng J 398:124341

Sun Z, Huang B, Li Y et al (2021) Nanoconfined methane flow behavior through realistic organic shale matrix under displacement pressure: a molecular simulation investigation. J Pet Explor Prod Technol. https://doi.org/10.1007/s13202-021-01382-0
Turner RG, Hubbard MG, Dukler AE (1969) Analysis and prediction of minimum flow rate for the continuous removal of liquids from gas wells. JPT 21(11):1475-1482

Wang Ke, Li H, Wang J, Jiang B, Chengzhong Bu, Zhang Q, Luo W (2017) Predicting production and estimated ultimate recoveries for shale gas wells: a new methodology approach. Appl Energy 216:1416-1431

Wang K, Jiang B, Li H, Liu Q, Chengzhong B, Wang Z, Tan Y (2020) Rapid and accurate dynamic reserves evaluation for different types of shale gas wells: production decline analysis methods. Int J Coal Geol 218:103359

Xiangguo LU, Bao CAO, Kun XIE et al (2021) Enhanced oil recovery mechanisms of polymer flooding in a heterogeneous oil reservoir. Pet Explor Dev 48(1):169-178

Zhibin W, Yingchuan Li (2012) Mechanism of continuous fluid carrying in gas wells. Acta Pet Sin 33(4):681-686

Publisher's Note Springer Nature remains neutral with regard to jurisdictional claims in published maps and institutional affiliations. 